\title{
AN ESTIMATION OF THE FACTORS OF SCHOOL CLIMATE IN SECONDARY SCHOOLS: A CONFIRMATORY FACTOR ANALYSIS MODELLING
}

\author{
HABIBAT ABUBAKAR YUSUF ${ }^{1}$, ISMAIL HUSSEIN AMZAT ${ }^{2} \&$ KHALIZA BINTI SAIDIN $^{3}$ \\ ${ }^{I}$ Department of Educational Management, University of Ilorin, Nigeria \\ ${ }^{2}$ School of Education and Modern Languages, University Utara Malaysia, Malaysia \\ ${ }^{3}$ School of Education and Modern Languages, University Utara Malaysia, Malaysia
}

\begin{abstract}
The focus of this study is to estimate and develop a model and also confirms the theory of school climate in secondary schools, Nigeria through a confirmatory factor analysis approach. The model in this study was developed to explore and confirm the theory using Taguiri's taxonomy, to confirm the factor of school climate to show if these factors are through measure of school climate and related to each other. Three hundred and fifty questionnaires were returned, valid and completed out of the 500 questionnaires distributed to participants. The data were analysed based on the perception of the respondents using a confirmatory factor analysis in the structural equation modelling. The results of the findings conclude that the constructs were true and valid measures of the latent construct of school climate.
\end{abstract}

KEYWORDS: School Climate, Ecology, Milieu, Social System, Culture \& Secondary School

Received: Sep 13, 2017; Accepted: Sep 30, 2017; Published: Oct 26, 2017; Paper Id.: IJESRDEC20171

\section{INTRODUCTION}

Education policy makers have gone to considerable lengths over the past several decades to target their policies at a technical core of schooling by specifying what teachers should teach, at times how they should teach, management of schools and acceptable levels of mastery for students - their initiatives. This represents a considerable shift in the policy environment of schools, which ultimately depend on school administration for their successful implementation (James \& Allison, 2012). A school as an organization is value driven with techniques and structures aiming to train the younger generation to solve their immediate problems and perform social responsibility (Aslanargun, 2012). It has a large group of people with different traits, attributes and characteristics which operates an open system with democratic control with internal and external factors which often press on the system for its smooth operation. The commitment and support of this individual will strengthen the school system and foster the relationship among staff and students, which may result to a better outcome in the system. Therefore, stakeholders in school depend on institutional climate and existing features which include school history, available resources, students and staff that work there for smoother operation.

Over the years, there have been a wide range of theories used to describe school climate which has complicated how its measured (Thapa, Cohen, Guffey, Higgins-D'Alessandro 2013), as the results obtained from empirical researches, that correlates school climate to effectiveness were also contradictory and consequently, researcher have concluded that, further investigation is required to examine factors responsible for negative climate in schools, (Guffey, et al 2013; Oyetunji, 2006). Similarly, a clearer examination of previous studies reviewed shows that show that most school climates researches neglect the aspects of teacher characteristics, morale and 
stability, as well as physical and material resources. They focus more on the social system and cultural dimensions, Tubbs \& Garner, (2008). Hoy et.al (2013) described school climate as the perceptions of the general work environment of the school as well as its quality as experienced by the head, teachers, students and other stakeholders. It reflects norms, goals, values, interpersonal relationships, teaching and learning practices, and organizational structures based on peoples' various experiences and feelings of school life which should foster development, productive learning and satisfying life in school (Cohen, Mccabe, Michelli, Pickeral, 2009). It also involved various aspects of school life such as safety, relationships, school environment and most importantly, teaching and learning (Wang \& Degol, 2016).

A growing body of academic researches has advanced variations and diverging opinions on definitions of school climate, yet in all of the definitions, there exists a substantive similarity in all components, although many past researches (Halphin \& Croft, 1963; Mitchel, 1968; Sinclair, 1970; Anderson, 1970; Willower, 1977, Wynne, 1980) focus more on the social system and cultural aspect of school climate. Through a review of research, Halphin \& Croft, (1963) perceived school climate based on principal-teacher related factors like a hindrance, intimacy, aloofness, consideration, production, thrust, disengagement and esprit. Thus, according to Anderson (1982) were categorized as a social system and culture. Also, Hoy, Smith \& Sweetland, (2002) found four encompassing constructs that make up the concept of school climate. These domains are: principal leadership, teacher, achievement press for student to perform academically; and vulnerability to the community. Similarly, Wheelock (2005) studied climate in four dimensions which include: supportive behaviour, directive behaviour, restrictive behaviour, and principal openness. Truly, educators has recognized the significance of school climate for several decades, several other researchers have developed a comparable categorization to conceptualize the school environment (Barker \& Gump 1964; Moos 1973; Insel \& Moos 1974, Freiberg \& Stein, 1999).

A comprehensive research studies on school climate was reviewed by Anderson (1982) with a summary of variables related to climate as derived from Taguiri's taxonomy. The taxonomy of climate-related terms developed by Taguiri (1968) is preferable because it gives a precise and broader specification of constructs that deals with the entire attributes of the school system (Anderson, 1982) and also provided an effective system for organizing the school climate literature, thus, it serves as the theoretical basis for this study due to its comprehensiveness. This taxonomy includes:(a) ecology - physical and material aspect of the school environment (building and facilities, materials and equipment, financial incentives and special services); (b) milieu - the dimension of characteristics of individuals and groups in the school (their satisfaction and well-being); (c) social system - the social dimension concerned with pattern and operational rules guiding interactions in the school (administrative practices, supervisory relation, school-community relationship, performance and development); and (d) culture - concerned with beliefs, values, orientation, school activities and attitude towards the environment, Anderson (1982).

This study, therefore measures Taguiri's taxonomy of school climate, using the confirmatory factor analysis approach in Structural Equation Modelling (SEM). The proposed model will therefore, evaluate school climate based on the four-encompassing means, found within an organization. This would possibly provide an overall assessment of the constructs, by using a combination of the four factors (ecology, milieu, social system and culture) proposed by Tagiuri (1968). Hence, this study will identify, illustrate and confirm the latent constructs of school climate, through the concept of Taguiri's 1968 taxonomy, using the confirmatory factor analysis. 


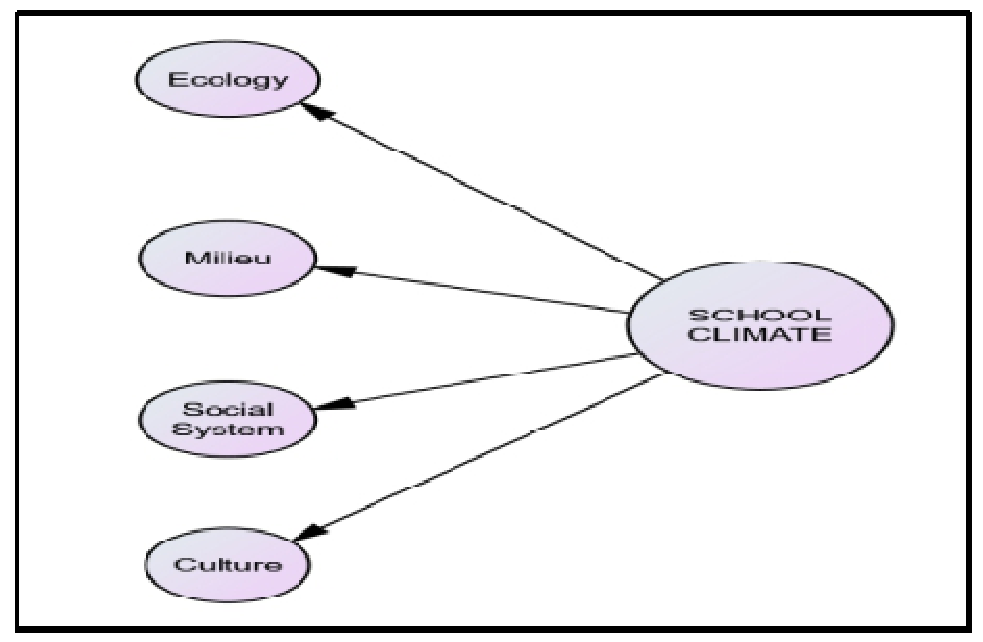

Figure 1: Theoretical Model

The above figure represents the model of school climate as stipulated in the theory. The school climate which is the latent constructs is having four dimensions (each factor is measured with questionnaire items) to represent the construct. The arrows pointing outward indicated that the latent construct cannot be directly measured. As a substitute, it is measured using four sub-constructs, (each having certain questionnaire items) which are the components of the school climate.

\section{METHODOLOGY}

Contrasting the usual practice of using a regression model, this study applied a second generational statistical technique of structural equation modelling. It was found suitable due to its efficiency and flexibility in taking a confirmatory approach to theory. It allows for a pictorial modelling of constructs for clearer conceptualization of theories, provides a convenient way of describing the latent constructs of an observed variable under study and examine the goodness of fit of a model (Awang, 2015; Bryne, 2001; Hair, Ringle \& Sarstedt, 2013). The study was conducted in Kwara State secondary schools, Nigeria with a total number of 350 teachers, who participated in the study. The questionnaire used in this study was adapted from the study of Ruane (1995) and Coughlan (1970) and modified to suit the context of the study. The items were having a unique code for easier identification, analysis and interpretation. The first step was to test for the reliability of the instrument to substantiate the findings of this study, through pilot study of a sample of 60 teachers in secondary schools. The total score of all items was computed, in order to estimate the consistency of the instrument using Cronbach's alpha correlation coefficient. The overall scale was having an alpha value of.855. The instrument contains 39 items, statements for all constructs. There were 10 question items each to measure ecology, social system and culture except for milieu, which consists of 9 statements. All statements were rated using a 7-point Likert Scale substantiated, by Sauro and Dumas (2009) ranging from Entirely Disagree (1), Mostly Disagree (2), Somewhat Disagree (3), Neither Agree nor Disagree (4), Somewhat Agree (5), Mostly Agree (6), to Entirely Agree (7) to reflect a robust and true evaluation of the respondent.

\section{DATA ANALYSIS AND RESULTS}

As stated earlier, this study is conducted to estimate and confirm the theory of school climate as specified in the model; hence the analysis is done in three stages. First is to examine the dimensionality of items and reduce redundant data in the questionnaire and check for consistency of structure with the data through the Principal Component Analysis (PCA) 
using varimax rotation in the Statistical Package, for Social Sciences (SPSS 23.0). Secondly, the items retained in PCA were transferred to the AMOS graphic 23.0 for validation using Confirmatory Factor Analysis (CFA) as proposed in the study. Lastly, the model fitness for the measurement model was established and reported in the study through Structural Equation Modelling.

Table 1: Factor Analysis of School Climate

\begin{tabular}{|c|l|c|c|c|c|c|}
\hline Item Code & \multicolumn{1}{|c|}{ Measurement Items } & \multicolumn{2}{|c|}{ Factor Loadings } & \% of Variance \\
\hline CT3 & School recognizes my efforts & .841 & & & & $75.28 \%$ \\
\hline CT1 & Equal opportunity to student & .823 & & & & \\
\hline CT4 & Show respect for student cultural believes and practices & .798 & & & & \\
\hline CT5 & Work reviewed & .768 & & & & \\
\hline CT6 & Arrive school ahead of schedule & .718 & & & & \\
\hline SS4 & Discuss educational goals with principal & & .813 & & & \\
\hline SS5 & Work together with other togethers & & .740 & & & \\
\hline SS3 & Socialize with other teachers outside school & & .722 & & & \\
\hline SS2 & Monitor students' progress frequently & & .687 & & & \\
\hline SS1 & Observe others while teaching & & .528 & & & \\
\hline EC7 & Shortage of instructional materials & & & .829 & & \\
\hline EC9 & Lack of fund in introducing up-to-date materials & & & .814 & & \\
\hline EC8 & Equipment are kept in usable condition & & & .650 & & \\
\hline EC10 & School supplies available to students & & & .580 & & \\
\hline ML8 & Show greater concern for other colleagues & & & .836 & \\
\hline ML7 & Students behave responsibly & & & .716 & \\
\hline ML9 & I am appreciated by other colleagues & & & .609 & \\
\hline Kaiser-Meyer-Olkin Measure of Sampling Adequacy. & & & & \\
\hline Bartlett's Test of Sphericity: Approx Chi-Square & & & & \\
\hline
\end{tabular}

The initial school climate was measured with a 39 item scale. However, in order to ensure that, all factors are loaded under their own construct, the PCA was conducted using SPSS 23.0. After performing the PCA, four factors were combined and having a cumulative variance, explained of $75.279 \%$ having an eigen value greater than $>1$ (see table 2). Six items having cross loading was excluded, while the remaining 16 items were having factor loading less than .50 and were expunged, therefore twenty-two items in all were removed from the overall scale as evidently revealed in the table. The Bartlett's Test of Sphericity for all constructs were significant at .000 , with P-value $<0.05$ and the Kaiser-Meyer-Olkin measure of sampling adequacy, which shows the proportion of variance among variables measures .917, which is greater than.6, thus, representing a high level of sampling adequacy for factor analysis, hence, the value was within the required range, which makes data more suitable $(\mathrm{N}=419)$. Therefore, it is appropriate to proceed with the structural equation modelling.

Table 2: Total Variance Explained for School Climate

\begin{tabular}{|l|c|c|c|c|c|c|}
\hline \multirow{2}{*}{ Component Initial Eigen Values } & \multicolumn{3}{c|}{ Extraction Sums of Squared Loadings } \\
\cline { 2 - 7 } & Total & \% of Variance & Cumulative \% & Total & \% of Variance & Cumulative \% \\
\hline CT3 & 9.167 & 53.921 & 53.921 & 9.167 & 53.921 & 53.921 \\
\hline CT1 & 1.596 & 9.390 & 63.310 & 1.596 & 9.390 & 63.310 \\
\hline CT4 & 1.176 & 6.919 & 70.230 & 1.176 & 6.919 & 70.230 \\
\hline CT5 & .858 & 5.049 & 75.279 & .858 & 5.049 & $\mathbf{7 5 . 2 7 9}$ \\
\hline CT6 & .671 & 3.950 & 79.229 & & & \\
\hline SS4 & .645 & 3.792 & 83.021 & & & \\
\hline SS5 & .469 & 2.758 & 85.780 & & & \\
\hline
\end{tabular}




\begin{tabular}{|l|l|l|c|l|l|l|}
\hline \multicolumn{7}{|c|}{ Table 2: Contd., } \\
\hline SS3 & .420 & 2.471 & 88.250 & & & \\
\hline SS2 & .351 & 2.062 & 90.313 & & & \\
\hline SS1 & .305 & 1.794 & 92.107 & & & \\
\hline EC7 & .291 & 1.713 & 93.820 & & & \\
\hline EC9 & .230 & 1.355 & 95.175 & & & \\
\hline EC8 & .203 & 1.194 & 96.369 & & & \\
\hline EC10 & .194 & 1.143 & 97.512 & & & \\
\hline ML8 & .159 & .938 & 98.450 & & & \\
\hline ML7 & .135 & .794 & 99.245 & & & \\
\hline ML9 & .128 & .755 & 100.000 & & & \\
\hline
\end{tabular}

\section{MEASUREMENT MODEL}

Structural equation modelling is used in this study for its capability to assess and correct for measurement errors, it allows for the use of multiple measures to represent constructs and finally, it takes a confirmatory, rather than an exploratory approach to data analysis (Byrne, 2001; Schumacker \& Lomax, 2004). Initially data were checked and screened for missing values, outliers, and normality distributions according to the guidelines provided by (Hair, Black, Babin, \& Anderson, 2010) through version 23.0 of the SPSS. Thereafter, the measurement model was established through confirmatory factor analysis to ascertain how fit the model is with the sampled data. Although, there are no unanimously agreed fitness indexes to report on a study, Awang (2016) and Hair et al. (2010) recommend using at least one from all categories of the model fit (absolute, parsimonious and incremental fits). In spite of this, Bryne (2010) posited that, fitness indices alone may not probably enclose the usefulness and adequacy of a model fits to its sample data, rather assessing model fit should be based on multiple criteria, that reflects theoretical, statistical and practical considerations

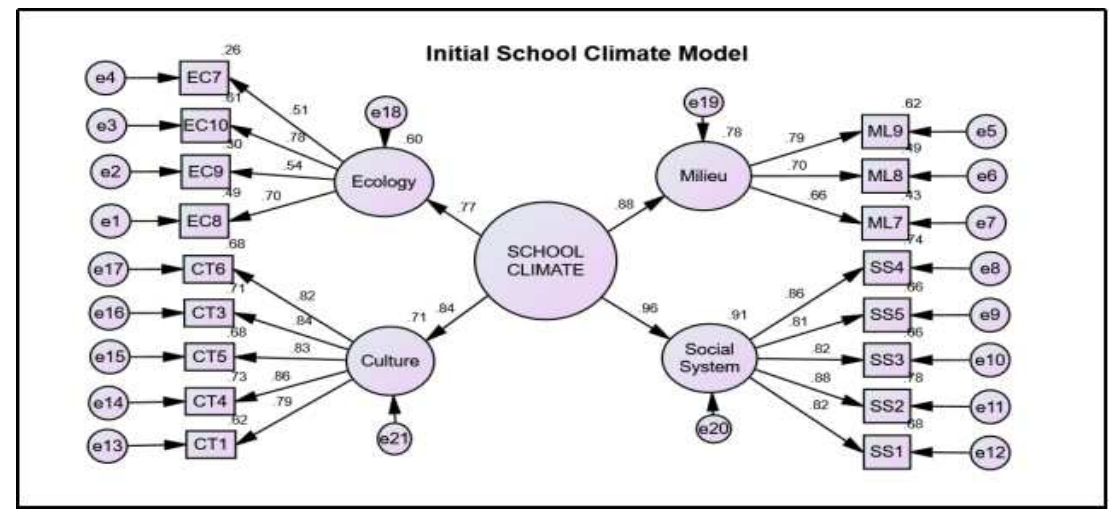

Figure 2: Initial Model of School Climate

School Climate was measured, based on four factors of ecology, milieu, social system and culture comprising of 17 observed variables. Although, all values of factor loadings for the initial measurement model of school climate are greater than.50, it however, revealed that the data did not fit the model appropriately. The fitness indexes indicated that, the model was unacceptable $\left(\mathrm{CMIN}=513.715 ; \mathrm{df}=113 ; \chi^{2} / \mathrm{df}=4.5 ; \mathrm{GFI}=0.840 ; \mathrm{AGFI}=0.783 ; \mathrm{CFI}=0.889 ; \mathrm{TLI}=0.867\right.$; $\mathrm{IFI}=0.888 ; \mathrm{NFI}=0.863$ and RMSEA $=0.107)$. Thus, there was a need for modification.

However, since the fitness indexes obtained from the initial model does not meet the required level (see table 3), some items considered problematic were expunged from the model. Two items each were from social system and culture (SS1 - I observe others while teaching, SS2 - I monitor students' progress frequently, CT3 - School recognizes my efforts, CT6 - I arrive school ahead of schedule). Additionally, the modification indices were examined to check for redundant 
items in the model. Two redundant items were found in error 2 and error 4, to have modification index value of $63.168>$ 15 and considered very high; they were therefore set as free parameters in the model. The correlation of e 2 and e4 (Shortage of instructional materials and Lack of fund in introducing up-to-date materials) finally improved the model fit statistically when and the new measurement model was re-estimated (see figure 3).

Table 3: Measures for Model Fit Indexes

\begin{tabular}{|c|c|c|c|c|}
\hline \multirow[b]{2}{*}{$\begin{array}{c}\text { Category of } \\
\text { Measure }\end{array}$} & \multirow[b]{2}{*}{ Index } & \multicolumn{2}{|c|}{ Observed Scores } & \multirow{2}{*}{$\begin{array}{c}\text { Recommended Value } \\
\text { (Hu and Bentler, 1999); Hair et al. }, \\
\text { 2010) }\end{array}$} \\
\hline & & $\begin{array}{c}\text { Before } \\
\text { Modification }\end{array}$ & $\begin{array}{c}\text { After } \\
\text { Modification }\end{array}$ & \\
\hline \multirow{5}{*}{ Absolute fit } & Chi-Square/(CMIN) & 513.715 & 166.675 & $\begin{array}{l}\text { Near to degree } \\
\text { of freedom }\end{array}$ \\
\hline & Df & 113 & 58 & The greater, the better \\
\hline & $\left(\chi^{2} / \mathrm{df}\right)$ & 4.546 & 2.874 & $<3 ;$ or $<5$ \\
\hline & GFI & 0.840 & 0.921 & $>0.90 ;>0.80$ \\
\hline & RMSEA & 0.107 & 0.07 & $<0.05$ to 0.10 \\
\hline \multirow{3}{*}{ Incremental fit } & CFI & 0.889 & 0.945 & $>0.90$ \\
\hline & NFI & 0.863 & 0.920 & $>0.90$ \\
\hline & AGFI & 0.783 & 0.880 & $>0.90 ;>0.80$ \\
\hline \multirow{2}{*}{ Parsimonious fit } & PGFI & 0.620 & 0.591 & The higher, the better \\
\hline & PNFI & 0.739 & 0.687 & The higher, the better \\
\hline
\end{tabular}

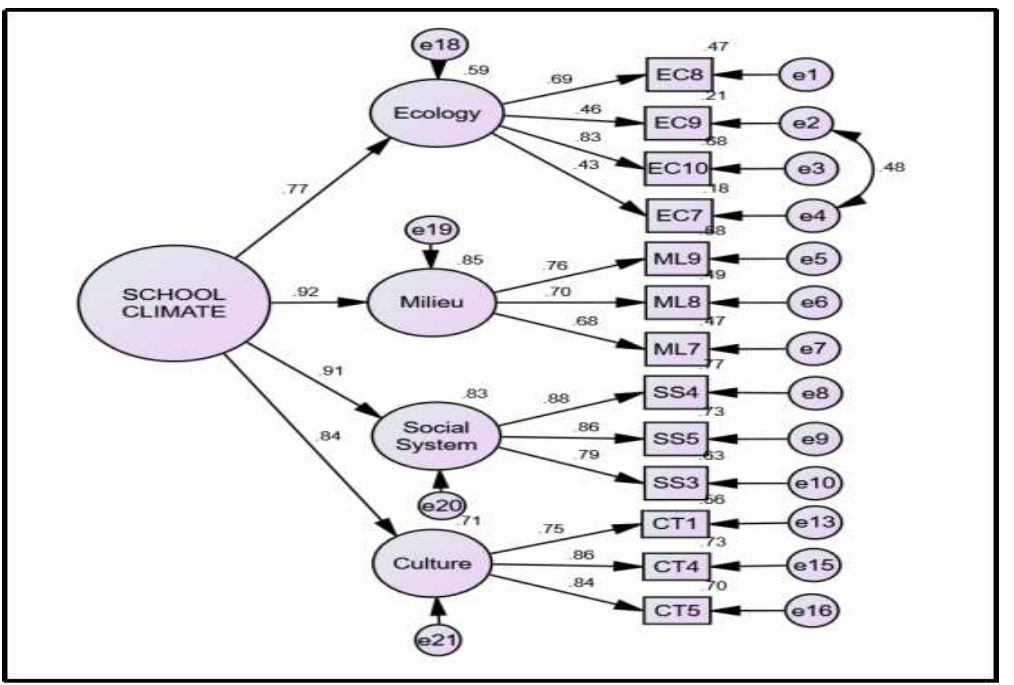

Figure 3: Final School Climate Model

In the final measurement model (figure 3), the absolute fit index for the model shows that the recommended values were met in the model. The Goodness Fit Index (GFI) fall in the range of $>0.90$ and $>0.80$ which shows a good fit. The incremental fit index as shown in the CFI and AGFI value of 0.945 and 0.880 respectively, are close to 1 , indicating a good fit. Similarly, the RMSEA value shown in the figure is also within the acceptable range of.05 and.10 that revealed a good fit. The squared multiple correlation values (. 47-EC8, .21-EC9,.68-EC10,.18-EC7;.58-ML9,.49-ML8,.47-ML7;.77SS4,.73-SS5,.63-SS3,.66-CT1, .73-CT4,. 70-CT5) which shows the extent to which the observed variable variance is explained by the latent construct is having high loading. Furthermore, the convergent validity of the model was examined using factor loadings, squared multiple correlations $\left(R^{2}\right)$, the average variance extracted (AVE) for all factors in this study. The standardized factor loadings for all items is between 0.421 and 0.875 which is greater than the suggested threshold of 0.35 (Hair et al., 1995), and the AVE which explains the average percentage of variation in items to a construct is greater 
than the required threshold of 0.50 (Awang, 2015). Therefore, the convergent validity of the model is attained. This, according to Holmes-Smith (2001) is accomplished when the factor loading considerably differs from zero and values of AVE exceed 0.50, hence, it indicates a good model fit and good convergent validity (see table 4).

Table 4: Results of CFA

\begin{tabular}{|l|l|c|c|c|}
\hline Factor & Items/Indicator & Factor Loadings & $\mathbf{R}^{2}$ & Average Variance Extracted (AVE) \\
\hline \multirow{4}{*}{ Ecology } & EC7 & 0.421 & 0.177 & \\
\cline { 2 - 4 } & EC8 & 0.679 & 0.461 & \multirow{3}{*}{0.731} \\
\cline { 2 - 4 } & EC9 & 0.452 & 0.204 & \\
\cline { 2 - 4 } & EC10 & 0.838 & 0.702 & \\
\hline \multirow{3}{*}{ Milieu } & ML7 & 0.684 & 0.468 & \multirow{2}{*}{0.568} \\
\cline { 2 - 4 } & ML8 & 0.709 & 0.503 & \\
\cline { 2 - 4 } & ML9 & 0.758 & 0.575 & \\
\hline \multirow{3}{*}{ Social System } & SS4 & 0.789 & 0.623 & \multirow{2}{*}{0.773} \\
\cline { 2 - 4 } & SS3 & 0.875 & 0.766 & \\
\cline { 2 - 4 } & SS5 & 0.859 & 0.738 & \\
\hline \multirow{3}{*}{ Culture } & CT1 & 0.752 & 0.566 & \multirow{2}{*}{0.606} \\
\cline { 2 - 4 } & CT4 & 0.858 & 0.736 & \\
\cline { 2 - 4 } & CT5 & 0.832 & 0.692 & \\
\hline
\end{tabular}

\section{CONCLUSIONS}

The rationale for this study is to estimate and confirm the theory of school climate. The study focuses on and verified Taguiri (1968) Taxonomy of Climate by building, estimating, and verifying a model, to measure the factors related to school climate through a confirmatory factor analysis approach. The study was essentially conducted in secondary schools in Kwara State, Nigeria, whereby teachers responded to the survey questions. The analysis done through the confirmatory factor analysis suggested that, each item in the four latent constructs (ecology, milieu, social system and culture) was having acceptable factor loadings, ranging from $0.421-0.875$ on their unobserved variables. The model fit indices examined were all within the acceptable range; hence, the data fits the model which further confirms that, the four factors of Taguiri (1968) are true measures of school climate. Therefore, secondary schools may adopt this theory, in studying the climate of the school environment.

\section{REFERENCES}

1. Anderson, C. S. (1982). The Search for school climiate: A review of the literature. Review of Educational Research, 52(3), 368-420. https://doi. org/10.3102/00346543052003368

2. Aslanargun, E. (2012). Principals' values in school administration. Kuram ve Uygulamada Egitim Bilimleri, 12(2), 13391344.

3. Awang, Z. (2015). SEM made simple (First). Selangor: MPWS Rich Publication Sdn Bhd.

4. Barker, R. G., \& Gump, P. V. (1964). Big school, small school: High school size and student behaviour. California: Stanford University Press.

5. Byrne, B. M. (2001). Structural Equation Modeling With AMOS, EQS, and LISREL: Comparative Approaches to Testing for the Factorial Validity of a Measuring Instrument. International Journal of Testing, 1(1), 55-86.

6. Cohen, J., McCabe, E., Michelli, N., \& Pickeral, T. (2009). School climate: Research, policy, teacher education and practice. Teacher College Record. 111(1), 180-213.

7. Coughlan, R. J. (1970). Dimensions of Teacher Morale. American Educational Research Association, 7(2), $221-234$. 
8. Freiberg, J. H., \& Stein, T. A. (1999). Measuring, improving and sustaining healthy learning environments. In J. H. Freiberg (Ed.), School Climate: Measuring, improving and sustaining healthy learning environments (First, p. 231). Philadelphia: Falmer.

9. Hair, J. F., Black, W. C., Babin, B. J., \& Anderson, R. E. (2010). Multivariate Data Analysis. Vectors (7th ed.). Pearson Prentice Hall. https://doi. org/10.1016/j. ijpharm.2011.02.019

10. Hair, J. F., Ringle, C. M., \& Sarstedt, M. (2013). Editorial-partial least squares structural equation modeling: Rigorous applications, better results and higher acceptance. Long Range Planning, 46(2), 1-12.

11. Homes-smith, P., (2001). Introduction to Structural Equation modelling using Lisreal. Acspri-Winter Training Program, Perth.

12. Hoy, W. K., Sweetland, S. R., \& Smith, P. (2002). Toward an Organizational Model of Achievement in High Schools: The Significance of Collective Efficacy. Educational Administration Quarterly, 38(1), 77-93. https://doi. org/10.1177/0013161X02381004

13. Insel, P. M., \& Moos, R. H. (1974). Psychological environments: Expanding the scope of human ecology. American Psychologist, 29(3), 179-188.

14. Mitchell, M. M., Bradshaw, C. P., \& Leaf, P. J. (2010). Student and Teacher Perceptions of School Climate: A Multilevel. Journal of School Health, 80(6), 271-280.

15. Ruane, M. L. (1995). The development of measure of school climate and its validation using a multimethod approach.

16. https://doi. org/10.1016/j. econedurev.2013.10.003

17. Sauro, J., \& Dumas, J. (2009). Comparison of Three One-Question, Post-Task Usability Questionnaires. In Proceedings of the SIGCHI Conference on Human Factors in Computing Systems (pp. 1599-1608). https://doi. org/10.1145/1518701.1518946

18. Schumacker, R. E., \& Lomax, R. G. (2004). Beginner's guide to structural equation modeling (Second). London: Lawrence Erlbaum Associates, Publishers.

19. Thapa, A., Cohen, J., Guffey, S., \& Higgins-D 'alessandro, A. (2013). A Review of School Climate Research. Review of Educational Research, 83(3), 357-385. https://doi. org/10.3102/0034654313483907

20. Tubbs, J. E., \& Garner, M. (2008). The impact of School Climate on School Outcomes. Journal of College Teaching \& Learning, 5(9), 17-26. Retrieved from http://www. Clute institute. Com/ojs/index. php/TLC/article/view File/1230/1214 